\section{ECCOMAS}

\section{Proceedia}

COMPDYN 2021

$8^{\text {th }}$ ECCOMAS Thematic Conference on Computational Methods in Structural Dynamics and Earthquake Engineering M. Papadrakakis, M. Fragiadakis (eds.)

\title{
EVALUATION OF THE SEISMIC VULNERABILITY OF EXISTING PRE-CODE RC CORE STRUCTURAL SYSTEMS THROUGH NON-LINEAR PUSHOVER ANALYSES
}

\author{
B. Belletti ${ }^{1}$, E. Martinelli ${ }^{2}$, E. Michelini ${ }^{1}$ and F. Vecchi ${ }^{1}$ \\ ${ }^{1}$ Department of Engineering and Architecture, University of Parma \\ Parco Area delle Scienze 181/A, 43123, Parma, Italy \\ e-mail: beatrice.belletti@unipr.it, elena.michelini@unipr.it, francesca.vecchi@unipr.it \\ ${ }^{2}$ Department of Civil Engineering, University of Salerno \\ via Giovanni Paolo II 132, 84084, Fisciano (SA), Italy \\ e-mail: enzo.martinelli@unisa.it
}

\begin{abstract}
In the last years, a growing attention has been devoted to the seismic vulnerability assessment of existing Reinforced Concrete (RC) framed buildings designed only for gravitational loads. The seismic behavior of existing framed buildings with an inner $R C$ stairwell core has been investigated much less so far, even if this structural typology has known a certain spread from the Seventies onwards, especially in the Italian largest urban areas. In this work, the seismic behavior a relevant and representative example of existing pre-code $R C$ core medium rise building is evaluated by performing nonlinear pushover analyses. The effect of different modelling assumptions regarding the degree of collaboration between frames and $R C$ walls on the structural response is discussed. The influence of masonry infills on the global structural response is also evaluated by running the analyses both on the bare structure and on a structural model considering a distribution of masonry panels not regular in elevation: the latter distribution corresponds to a typical situation for the considered typology.
\end{abstract}

Keywords: reinforced concrete, core systems, non-linear analysis, existing structures, infills.

ISSN:2623-3347 (C) 2021 The Authors. Published by Eccomas Proceedia. Peer-review under responsibility of the organizing committee of COMPDYN 2021. doi: $10.7712 / 120121.8543 .18692$ 


\section{INTRODUCTION}

A significant share of the existing Italian Reinforced Concrete (RC) building stock was designed for gravity loads only (so-called pre-code buildings), or according to now outdated seismic standards. Consequently, those buildings are generally vulnerable to seismic actions, often showing a non-ductile behavior, due to the non-optimal in-plan distribution of the structural elements (with frames only in one direction and stair cores often placed in an asymmetric position), poor structural details and material properties, deterioration phenomena due to environmental exposure conditions and to a limited maintenance over time.

During the past years, a lot of efforts were devoted to assessing vulnerability of existing $\mathrm{RC}$ framed buildings, which represent the most widespread structural typology within the RC building stock, not only in Italy, but also in several other seismic-prone countries in the Mediterranean area. The vulnerability of these structures is typically represented in terms of fragility curves, which express the probability of exceeding a predefined damage level for a wide range of ground motion intensities [1,2]. However, from the Seventies onwards, the presence of multi-story RC frames with shear walls realizing the elevator or stairwell core, has become increasingly common, especially in larger urban areas. It is well known that a correct in-plane disposition of the walls, together with an adequate choice of their dimensions and reinforcement, guarantees a good seismic response of modern RC structural wall buildings, reducing the inter-storey drift at damage limit state and providing enough ductility and strength at collapse. Nevertheless, in pre-code RC core structural systems, the position of elevator or stairwell core often creates structural irregularities and torsional actions, whose effects, together with the poor detailing of reinforcement (both in the walls and in the frame elements) should be carefully taken into account in vulnerability assessment studies. The specific features of existing core buildings, together with the high stiffness of the walls, make their seismic response quite different from that of framed structures, and consequently a different definition of the damage states used for the construction of fragility curves, as well as of the corresponding engineering demand parameters, may be required [3].

A further complication in the vulnerability assessment of these buildings is related to the presence of masonry infills. It is well known that infills significantly alter the seismic response of RC framed buildings, by producing a remarkable increase of lateral stiffness and base shear, as well as a reduction of the period of vibration. Moreover, their spatial arrangement within the framed structure can cause irregularities in the distribution of masses and stiffnesses, both in-plan and/or in elevation, with possible detrimental effects on the seismic response, as proved by observed damage data collected in post-earthquake surveys (i.e., among others, [4-8]). If almost uniformly distributed, infills can instead reduce the dissipation energy demands in frame elements, as well as the maximum displacements of the structure. For this reason, even if infills are traditionally treated as "non-structural" elements, it would be better to include their presence in numerical analyses, to allow a more realistic representation of the global behavior of the structure. Masonry panels are commonly schematized through equivalent nonlinear inclined struts, which represent a good compromise between accuracy and simplicity (i.e. [9-12]). The most of the studies available on this topic in the literature are however mainly focused on infilled RC frames, while the effect of masonry panels in case of framed buildings with an inner RC core has been less investigated so far. In this case, an irregular distribution of infills may alter the expected damage state sequence, due to the interaction between the infills themselves and the RC walls.

In this study analyzes the seismic response of a prototype pre-code RC 6-storey building with frames aligned in the longitudinal direction and $\mathrm{RC}$ walls realizing an internal asymmetric stair core. Pushover analyses are performed on the finite element model of the structure, by 
simulating frame components with beam elements and the shear walls with shell elements. The nonlinear behavior of $\mathrm{RC}$ walls is taken into account through PARC_CL_2.1 constitutive model [13], implemented into the finite element code ABAQUS [14]. The influence of different modelling choices on the global response of the building is explored, by considering the two alternative assumptions of linear elastic pendulum frames and non-linear collaborating frames. Moreover, the influence of infills and of their progressive damage on the global response is investigated, by highlighting their effects in terms of displacement capacity, global stiffness and strength.

\section{CASE STUDY}

The case study analyzed in this paper is a representative a typical pre-code RC 6-storey building, with frames aligned in the longitudinal direction and $\mathrm{RC}$ walls realizing an internal asymmetric stair core. The building has a rectangular plan, with dimensions equal to $11.7 \mathrm{~m} \mathrm{x}$ $24.4 \mathrm{~m}$, and a total height of $19.04 \mathrm{~m}$. An interstorey height of $3.06 \mathrm{~m}$ is assumed, except for the ground floor, where it is set equal to $3.74 \mathrm{~m}$. This lower level is partially underground. The framed structure consists of six bays in the longitudinal direction, with spans ranging between $2.8 \mathrm{~m}$ and $5.2 \mathrm{~m}$, and two bays with the same span (equal to $5.7 \mathrm{~m}$ ) in the transverse direction. As can be seen from the floorplan depicted in Figure 1, in transverse direction beams are present only in the external frames. The stairwell core, which is realized with $200 \mathrm{~mm}$ thick RC walls, has an asymmetric position in plan.

Slabs are composed with parallel RC joists, running through the transverse direction, and interposed hollow clay blocks, with a $400 \mathrm{~mm}$ thick RC topping. Over the last floor, an inclined roof is realized by means of masonry walls with variable height and ceramic flooring blocks. For intermediate floors, a dead load equal to $6.2 \mathrm{kN} / \mathrm{m}^{2}$ is assumed, and an additional permanent load of $2.0 \mathrm{kN} / \mathrm{m}^{2}$ is also applied to account for the presence of internal partitions; the live load is set equal to $2.0 \mathrm{kN} / \mathrm{m}^{2}$. For the last storey, a dead load of $7.2 \mathrm{kN} / \mathrm{m}^{2}$ and a live load of $1.2 \mathrm{kN} / \mathrm{m}^{2}$ (snow) are instead considered.

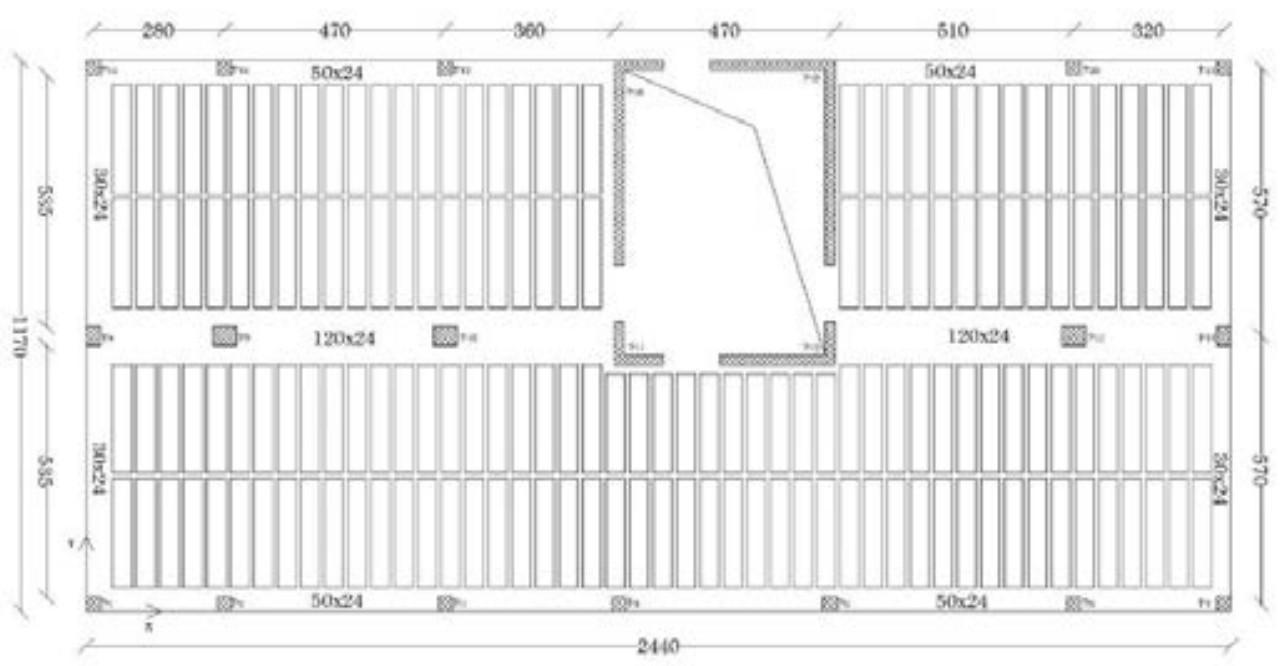

Figure 1: Typical floorplan of the examined case study building (dimensions in $\mathrm{cm}$ ).

The considered case study represents a typical Gravity Load Designed (GLD) building, without specific provisions for earthquake resistance. RC elements forming the frame are designed to sustain vertical loads only. Beams are realized within the thickness of the slab forming the floor $(240 \mathrm{~mm})$, and have a variable width, ranging from 300 to $500 \mathrm{~mm}$ for the 
external frames, and equal to $1200 \mathrm{~mm}$ for the internal one. Columns dimensions are typically equal to $300 \times 300 \mathrm{~mm}$ or $300 \times 400 \mathrm{~mm}$, except those belonging to the inner frame, which have a variable cross-section, ranging from $500 \mathrm{~mm} \times 400 \mathrm{~mm}$ at the lower storey, to $300 \mathrm{~mm} \times 400 \mathrm{~mm}$ at the top storey. The walls around the stairwell are conceived as a core system with high stiffness and are designed to sustain the wind load and a conventional horizontal action equal to $0.5 \%$ of the weights. As regards material properties, C25/30 concrete (with $\mathrm{f}_{\mathrm{cd}}=14.2 \mathrm{MPa}$ ) and B450 steel (with $\mathrm{f}_{\mathrm{y}}=391 \mathrm{MPa}$ ) are assumed. Further details on the considered case study structure can be found in $[15,16]$, to which reference is made.

Vertical closures of the buildings are realized by means of double layer brick infills, with a total masonry thickness of $(120+60) \mathrm{mm}$. Opening distribution within infills is depicted in Figure 2. Opening dimensions are assumed equal to $1.2 \times 1.3 \mathrm{~m}$. As can be seen, infills are assumed to be completely missing only in the rear side of the building (both on the right-hand and left-hand sides of the RC wall belonging to the core) at the lower level, so to allow the entry to garages. This not-regular infill distribution has been chosen since it is quite common for this type of buildings.

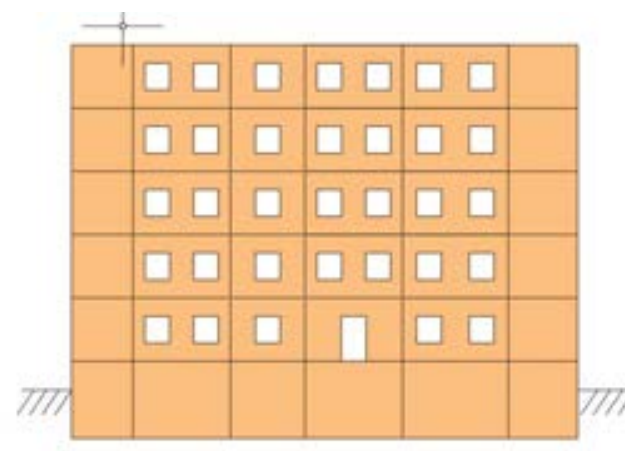

(a)

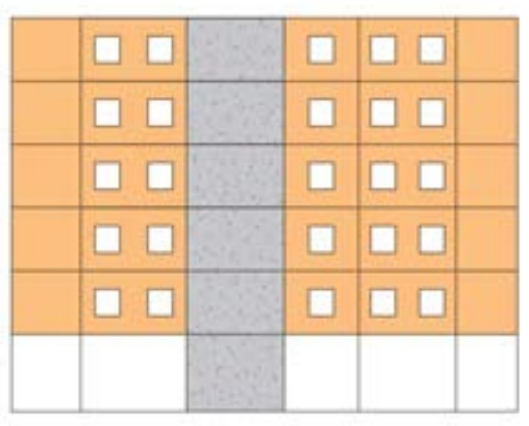

(b)

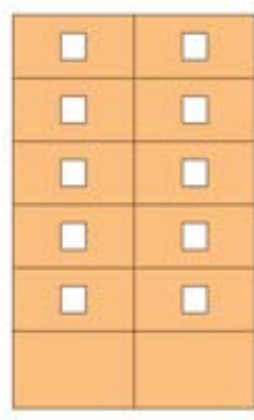

(c)

Figure 2: Sketch of the opening distribution within infill panels: (a) main façade; (b) rear side; (c) lateral side of the case study building.

\section{MODELLING ASSUMPTIONS}

The seismic behavior of the case study structure is studied by performing nonlinear pushover analyses, with the commercial Finite Element (FE) software ABAQUS [14].

As already highlighted, the considered building can be treated as a wall-equivalent dual system, since the elements belonging to the frame are designed for vertical loads only, while possible horizontal loads are mainly absorbed by the walls of the inner core. Taking in mind this aspect, two different models are realized, which are characterized by different complexity and different degree of interaction between the frame and the core during the earthquake. In Model $\# 1$, the collaboration of the frame in sustaining horizontal actions is completely disregarded, and all the sources of nonlinearity are simply assigned to the walls forming the core, while beams and columns are assumed as linear elastic. Regarding FE choices, pendulum frame components are modelled by using three-node beam elements with 2 integration points for columns, and 2-node truss elements with one integration point for beams.

In Model $\# 2$, the possible interaction between the frame and the core walls is explicitly taken into account (collaborating frame). In this case, beam elements are adopted for the modeling of all the frame component, with 3 nodes and 2 integration points for columns, and 2 nodes and 1 integration point for beams. The nonlinear response of beams and columns is dealt with a concentrated plasticity approach, and consequently they are modelled through elastic elements with rotational hinges at the ends. The assigned moment-curvature relation is 
calculated by adopting Saenz law with ultimate strain equal to $3.5 \cdot 10^{-3}$ for concrete and an elastic-perfectly plastic law for steel.

As concerns the presence of infills, the analyses are repeated twice, by considering two different configurations (Figure 3): the limit case of the bare structure (no infills present) and the "real" distribution of infills depicted in Figure 2.

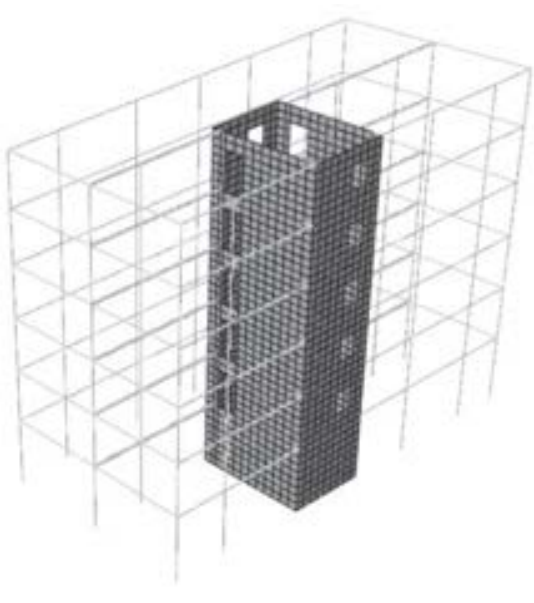

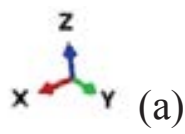

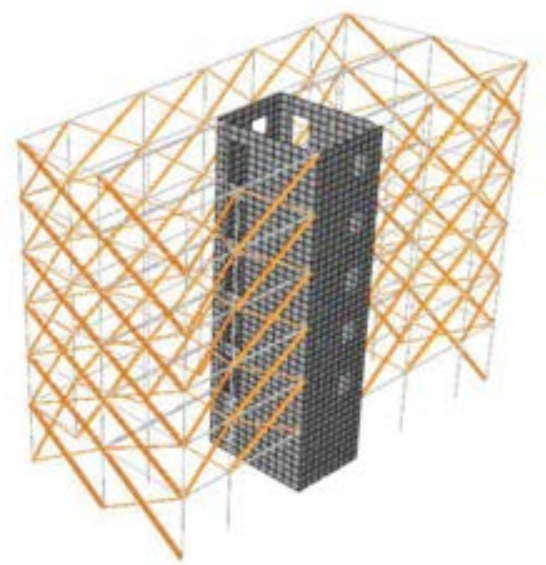

(b)

Figure 3: FE model: (a) bare structure; (b) structure with infills, according to the distribution depicted in Figure 2.

In this second case, the effect of infills on the global behaviour of the case study structure is assumed as equivalent to diagonal bracing, by adopting the single-strut model proposed in [12]. Each panel is replaced in the FE model by an equivalent pin-jointed diagonal strut, working only in compression, made with the same material of the infill and characterized by the trilinear lateral force-displacement relation shown in Figure 4a. The first branch of the curve represents the linear elastic response of the infill up to cracking, and its slope can be evaluated as:

$$
K_{i}=\frac{G_{w} L_{\text {in }} t_{w}}{H_{\text {in }}}
$$

as a function of the geometric dimensions of the infill (respectively being $L_{i n}, H_{i n}$ and $t_{w}$ the length, the clear height, and the thickness of the panel), and of the shear modulus of the masonry $G_{w}$.

The cracking force $F_{c}$ is assumed equal to 0.6 the maximum strength of the infill $F_{m}$, which is in turn expressed as:

$$
F_{m}=0.818 \frac{L_{i n} t_{w} f_{t p}}{C_{I}}\left(1+\sqrt{C_{I}^{2}+1}\right)
$$

with:

$$
C_{I}=1.925 \frac{L_{\text {in }}}{H_{\text {in }}}
$$

and being $f_{t p}$ the cracking strength of the infill (which can be determined from diagonal compression tests). It is assumed that the strength $F_{m}$ is reached at a storey drift equal to $0.2 \%$ and $0.15 \%$ respectively in case of infills without and with openings. It should be noted that Equations (1-2) are referred to the horizontal direction, and consequently it is necessary to transform them in the inclined direction $\theta$ to obtain the force-displacement envelope of the 
diagonal strut. The displacement at collapse is assumed equal to $5 D_{m}$, being $D_{m}$ the displacement corresponding to the maximum force (Figure 4a, [12]).

A further reducing coefficient is introduced to represent the presence of openings within the infills and to account for their effect on the initial stiffness and strength of the struts, having the following expression:

$$
\lambda_{0}=1-\frac{1.5 L_{0}}{L_{\text {in }}} \geq 0
$$

being $L_{0}$ the horizontal length of the opening. In this work, the following values are assumed for masonry properties: $G_{w}=1080 \mathrm{MPa}$ and $f_{t p}=0.3 \mathrm{MPa}$ for the external layer; $G_{w}=400 \mathrm{MPa}$ and $f_{t p}=0.1 \mathrm{MPa}$ for the internal one.

In order to reduce computational efforts, even if the infill panels are formed by a double masonry layer, only a single strut (instead of two superimposed struts) is considered, and its force-displacement relation is evaluated as the envelope of those of the two layers. Moreover, in order to insert this relation within the adopted FE code, it is further reworked and expressed in terms of stress vs. strain curve (an example is reported in Figure 4b).

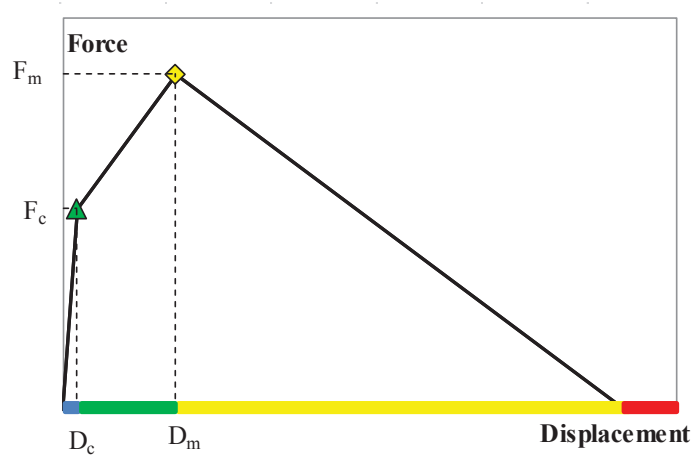

(a)

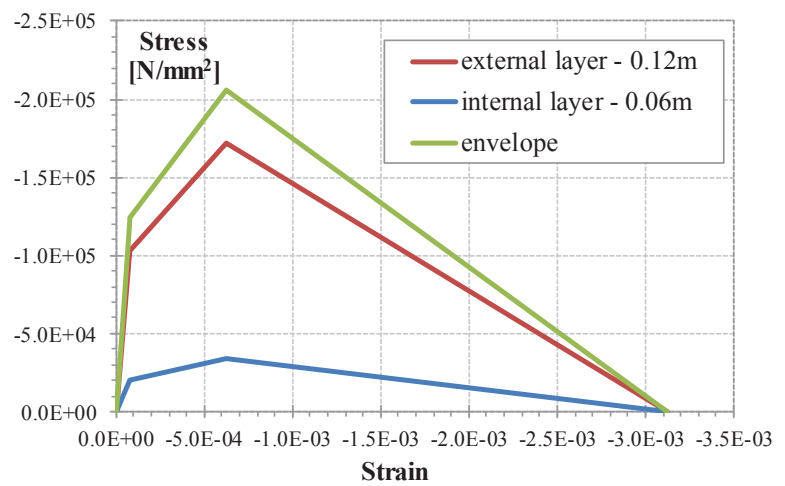

(b)

Figure 4: (a) Force-displacement relation for the diagonal struts representing the masonry infills (adapted from [12]; (b) implemented stress-strain law (referred to a strut of unit area), evaluated as the envelope of the two masonry layers.

In both Model \#1 and Model \#2, the RC walls of the core are modelled with 8-node, onelayered shell elements, with 4 Gauss integration point in the shell plane and 5 Simpson integration points in the thickness (element type S4R5). The nonlinear behavior of the walls under cyclic loads is considered by means of a user-defined constitutive law, named PARC_CL 2.1 [13], which is written in the form of a Fortran subroutine and implemented as a User MATerial (UMAT) in ABAQUS. PARC_CL 2.1 can be included in the framework of fixed smeared crack models, and it is based on a total strain formulation. The reinforcement is assumed to be smeared within the hosting concrete element through the reinforcement ratio $\rho_{\mathrm{s}}$. PARC_CL 2.1 was developed starting from a well-validated constitutive model for membrane elements subjected to general plane stresses, named PARC [17], which was previously conceived at the University of Parma for the analysis of RC structures under static loads. For static loads only, an alternative model based on a strain decomposition approach and named 2DPARC model is also available at the same University [18, 19].

PARC_CL 2.1 can be applied for the prediction of the cyclic and dynamic response of RC structures since it includes the effects of plastic and irreversible deformations in the unloading-reloading phase [20]. The model also allows to correctly catch other aspects which can be 
very important in the analysis of existing RC structures, such as the buckling of longitudinal reinforcement [21], time-dependent effects and the corrosion of reinforcement [22], which however lie outside of the scope of this work.

Finally, the presence of rigid diaphragms is included in the FE model by applying a kinematic coupling condition, which constrains the displacements of the nodes at each floor level to those of a reference "master" node. The maser node is herein assumed coincident with the bottom-left corner of the RC core.

\section{NLFEA: PROCEDURE, RESULTS AND DISCUSSION}

The behavior of the case study building under seismic actions is investigated by performing pushover analyses on the different FE models described in Section 3. To this aim, two lateral force distributions are considered: a uniform pattern (uniform response acceleration) and a triangular pattern (or modal pattern) proportional to the displacement shape of the first mode $[23,24]$. To take into account the effect of the accidental eccentricity of loads, by limiting at the same time the number of performed analyses, the center of mass is shifted away from its original position, so to maximize its distance from the center of stiffness. This new position of the center of mass is determined by combining the two accidental eccentricities in $\mathrm{X}$ and $\mathrm{Y}$ directions, calculated according to [24]. The lateral response is described in terms of base shear vs. top displacement relationship. The top displacement is set equal to the average of the values registered at two nodes, placed at the opposite corners of the roof floorplan, i.e. the upper-right and at the lower-left ones (Figure 1).

The results obtained from pushover analyses for Model \#1 and Model \#2 without infills are shown in Figure 5, with reference to lateral force distributions acting along the negative $\mathrm{X}$ and $\mathrm{Y}$ directions. As can be seen, Model \#2 is characterized by a higher bearing capacity with respect to Model \#1 when considering lateral forces acting in $-X$ direction, thanks to the additional resisting contribution offered by the three longitudinal frames. On the contrary, the lack of internal beams connecting the columns in the transverse direction makes almost negligible the bearing contribution of frame elements for seismic loads acting along $-Y$, and the global behavior is consequently governed by the walls belonging to the core. In both models, the asymmetric position of the internal core gives rise to torsional effects, as demonstrated by the deformed shape plotted in Figure 6, which is referred to Model \#2 without infills, for a uniform lateral load distribution respectively acting along $+\mathrm{X}$ and $+\mathrm{Y}$ direction.

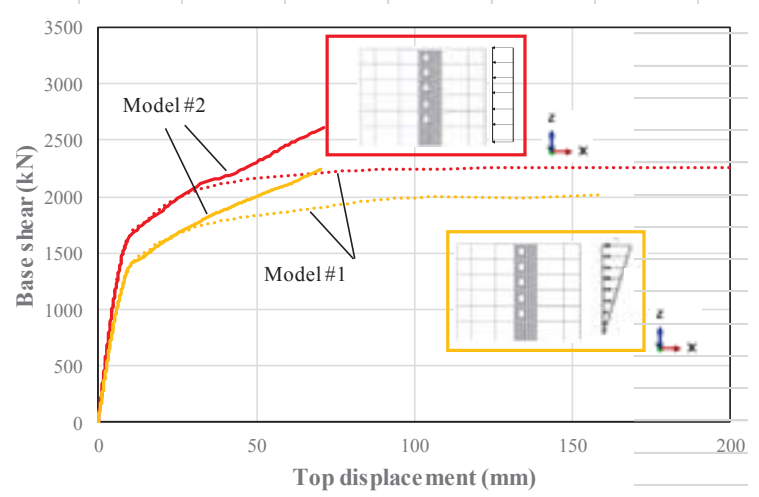

(a)

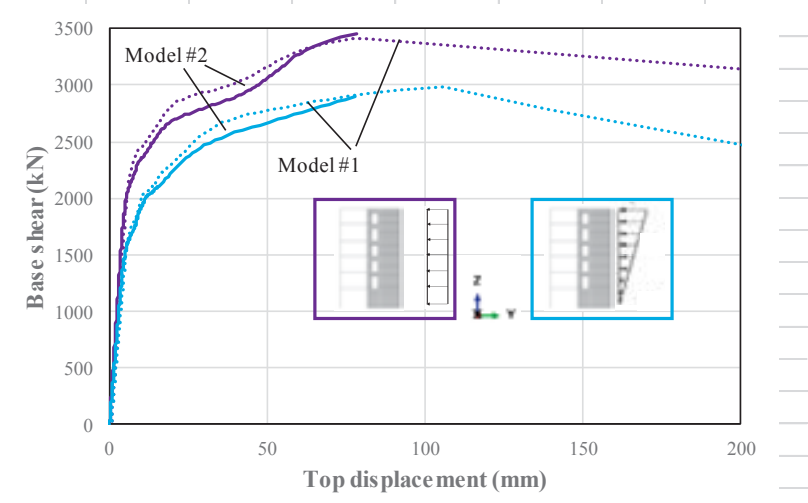

(b)

Figure 5: Base shear- top displacement curves obtained for Model \#1 and Model \#2 without infills from pushover analyses: (a) forces acting along $-\mathrm{X}$ direction; (b) forces acting along $-\mathrm{Y}$ direction. 


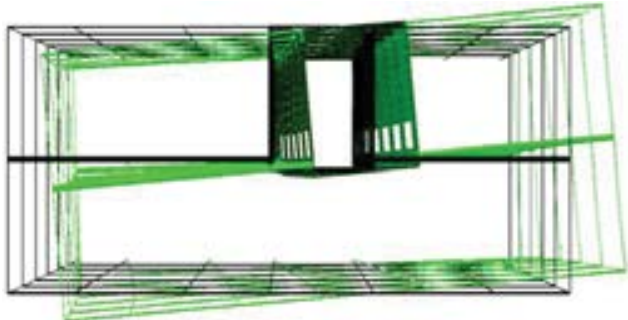

(a)

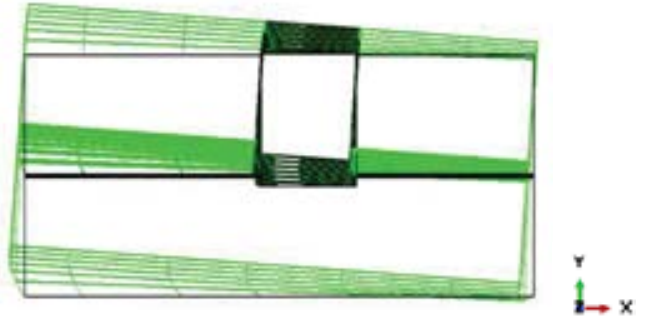

(b)

Figure 6: Deformed shape of the case study building obtained from Model \#2 without infills subjected to a uniform lateral load distribution acting along direction (a) $+\mathrm{X}$ and (b) $+\mathrm{Y}$.

The influence of infills on the global behavior of the structure is shown in Figure 7. For the sake of brevity, only the comparisons based on Model \#2 (with collaborating frames) are proposed in the case of uniform lateral load distribution acting in the $-X$ direction. To take into account the progressive damage of infills on the seismic response, the following procedure is proposed. At first, the analysis is carried out by considering the presence of infills according to the distribution depicted in Figure 2 ("Model \#2 with infills" in Figure 7). The results of the model are then elaborated so to detect the progressive degradation of infills panels. More in detail, the time increment corresponding to the achievement of the degrading branch of the force-displacement curve in some of the masonry panels is found, and the analysis is restarted from that increment, by removing the damaged infills through the ABAQUS option *MODEL CHANGE, REMOVE, and re-applying the horizontal load distribution. This operation is then repeated until almost all the infills are collapsed, so obtaining a sort of "envelope" curve ("Model \#2 with infills - progressive infill damage" in Figure 7). For comparison, an additional "lower-limit" curve is also plotted ("Model \#2 with infills - complete infill removal" in Figure 7), which is obtained by removing all the infills together, at the time increment corresponding to the first appearance of damage in some of them. It can be seen that the presence of infills greatly increase the lateral stiffness and strength of the structure; however, with the progressive damage of the panels, the base shear-top displacement curve obviously tends to superimpose that of the bare structure.

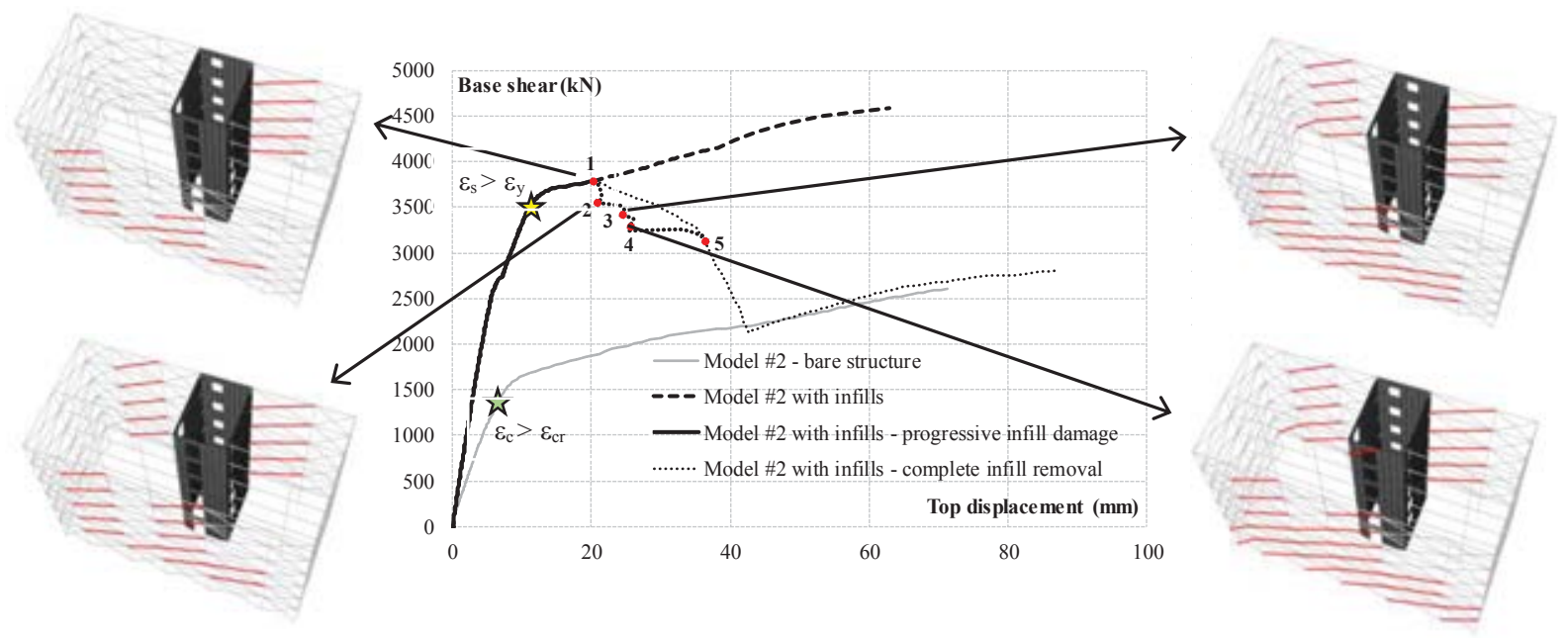

Figure 7: Base shear-top displacement curve for Model \#2 with and without infills, with indication of the progressive damage of masonry panels. 
The sequence followed for the removal of damaged infills (which are marked in red) is also sketched in Figure 7. It can be observed that the damage distribution within masonry panels is strictly related to the torsional deformation of the building under seismic loads (Figure 8), with a consequent stress concentration localized in some bays of the structure. Furthermore, it can be seen that the degrading branch of the force-displacement curve is reached before in those masonry panels characterized by a greater length $\mathrm{L}_{\mathrm{in}}$, where a higher number of openings is assumed according to Figure 2.
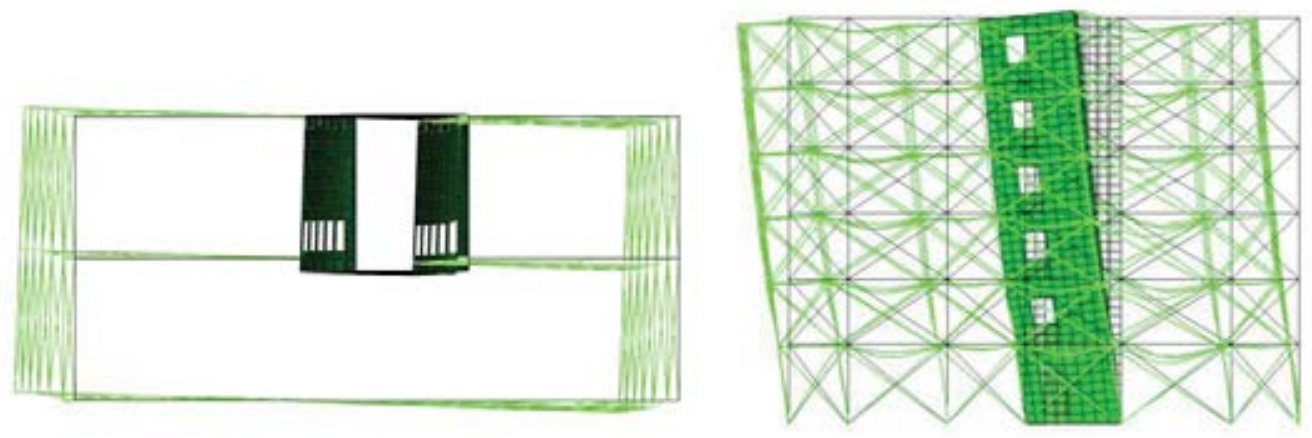

Figure 8: Deformed shape for Model \#2 with infills, corresponding to point 1 of the base shear-top displacement curve reported in Figure 7, when the fist panels start to damage.
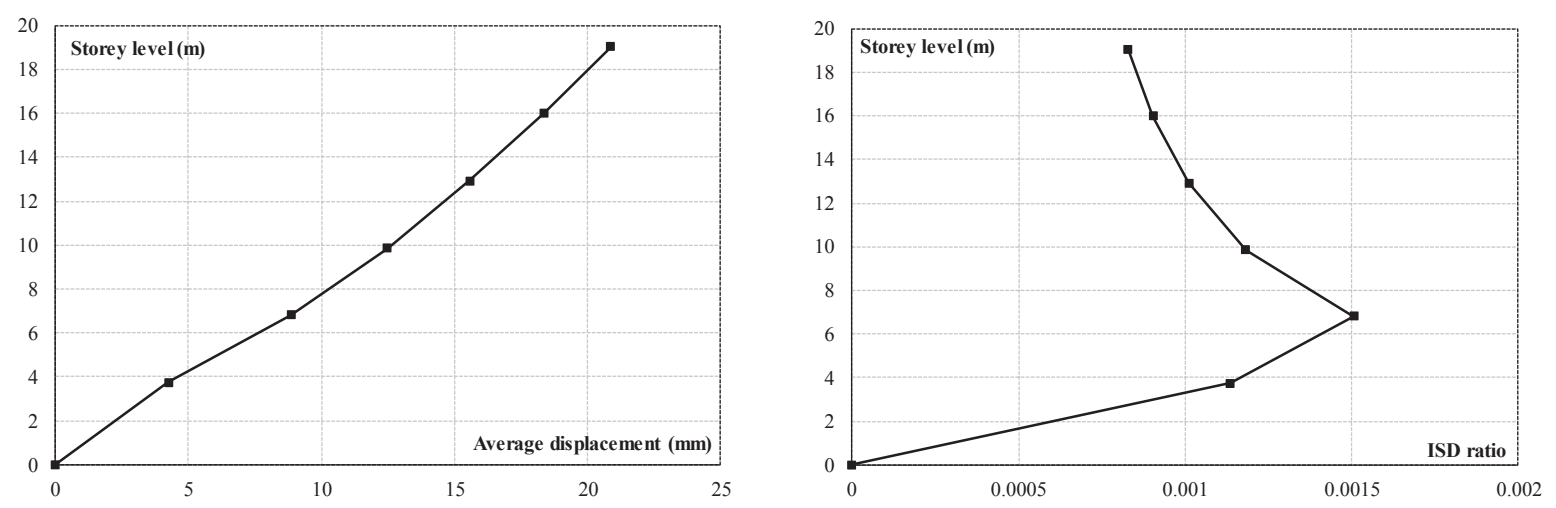

Figure 9: Displacement and inter-story drift profiles corresponding to point 1 in Figure 7.

In correspondence of point 1 in Figure 7, over 33\% (almost 45\% if referring only to the Xdirection) of the infill panels at the second storey have reached they maximum resistance and start to degrade. It can then be assumed that this point corresponds to the reaching of the socalled "Damage Limitation" state (DL LS, see, i.e., [4]), which is defined as a first limit state characterized by quite limited damage almost localized in non-structural elements, that should be easily and economically repaired (also known as slight damage state, LS1). The average values of lateral displacement profile corresponding to point 1 in Figure 7 are shown in Figure 9. The same Figure also reports the inter-storey drift ratio, evaluated as the average lateral displacement difference between two consecutive floors (inter-storey drift), divided by the height of the storey. The maximum obtained ISD ratio is comparable with the threshold values (typically ranging between 0.1 and $0.25 \%$ ) suggested in the literature to define the limit state corresponding to slight damage in numerical analyses on framed structures; these values are conventionally adopted when infills are not explicitly included in the FE model.

A further check on the model results reveals that when the first infills start to damage, yielding in RC elements of the frame has not been reached yet, and also the spreading of cracks in the RC walls of the core is very limited. On the contrary, yielding strain of longitu- 
dinal reinforcement is already registered in some portions of the walls (see Figure 10a; it should be noted that the condition $\varepsilon_{\mathrm{s}, \text { long }}>\varepsilon_{\mathrm{y}}$ is already reached for an average top displacement of $11 \mathrm{~mm}$, corresponding to the yellow star in Figure 7). This behavior can be explained in the light of the particular distribution considered for infills, which is not-regular in elevation on the rear side of the building, so producing a stress concentration in the RC walls. Moreover, the modelling technique adopted for infills (though diagonal struts) is probably not optimal in case of RC walls, since it may lead to concentrated loads on the shell elements connected to the nodes of the strut. In this specific case study, the not-uniform infill distribution is then responsible for a change in the expected damage sequence, since the yielding of the reinforcement of the walls (which corresponds to a moderate damage, LS2) is reached before the damage of masonry infills (corresponding to slight damage LS1). However, further analyses with different infill distributions are required to draw more general observations.

In a previous work [3] focused on the same structural typology (frame + inner core) investigated herein, the Authors have suggested as a possible criterion for the definition of slight damage limit state LS1 when infills are not explicitly included in the model, the reaching of the cracking strain in the RC elements of the shear walls, by following an approach conceptually similar to that described in FEMA 356 [25]. With reference to the pushover curve reported in Figure 7 ("Model \#2 - bare structure"), this criterion leads to the reaching of LS1 for an average top displacement value equal to $6.75 \mathrm{~mm}$ (green star in Figure 7). The ISD ratio profile corresponding to that situation is reported in Figure 10b, together with a contour showing the crack pattern in the core walls, as obtained from Model \#2 without infills. As can be seen, these values are lower than those commonly associated to infill damage in framed structures.
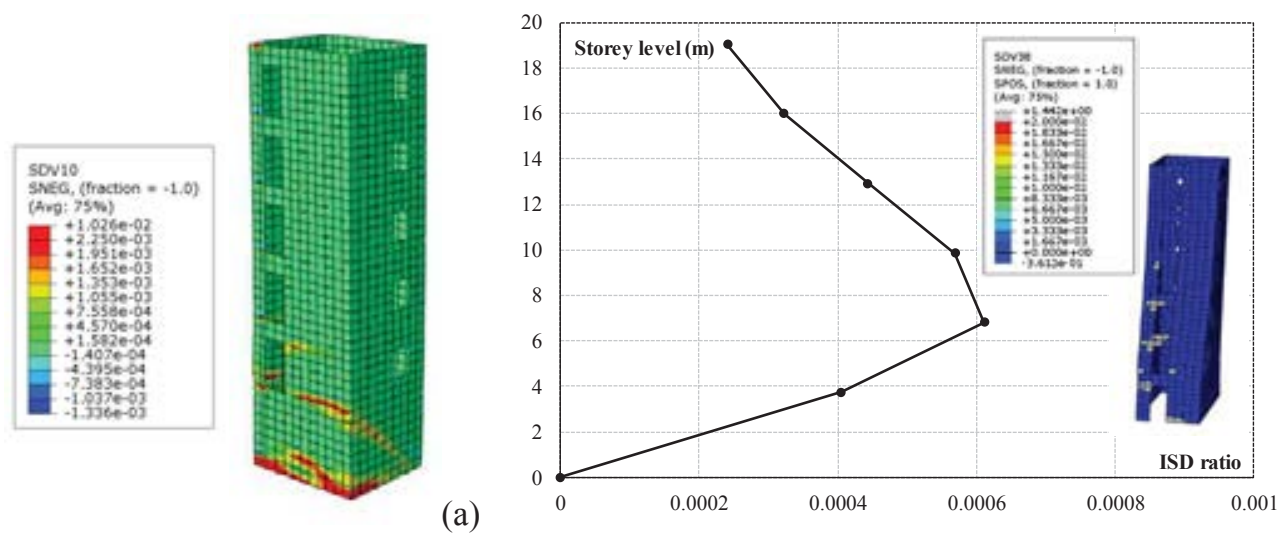

Figure 10: (a) Strain field in the longitudinal reinforcement of the walls corresponding to point 1 in Figure 7; (b) ISD ratio and crack pattern obtained from Model \#2 without infills, in correspondence of the green star of Fig. 7.

\section{CONCLUSIONS}

The results proposed in this paper confirm that presence of an asymmetric core, which is quite typical of pre-code RC buildings realized in large urban centers in the last 40 years, significantly affects the seismic response of the structure, giving raise to torsional effects. Specifically, the following main observations can be highlighted:

- The walls belonging to the core absorb the larger part of the lateral loads; however, the resistant contribution offered by frames (which are usually aligned in one direction only) is not negligible.

- The presence of infills modifies the global response of the structure, providing a remarkable increase the lateral stiffness and strength of the structure, as observed in framed 
structures. The reaching of the limit state corresponding to slight damage is often evaluated on the basis of the progressive appearance of damage in infills; when they are not explicitly included in numerical analyses, a conventional value of inter-story drift is often assumed. In case of framed structures with a RC core, alternative approaches, based on a material-level approach, can be also followed.

- Infill distribution has a great influence on the structural response and on the damage sequence taking place in structural and non-structural elements under seismic loads; further studies are required to draw general indications for the individuation of the damage states to be considered in derivation of fragility curves.

\section{REFERENCES}

[1] R. Maio, G. Tsionis, M. L. Sousa, S. Dimova, Review of fragility curves for seismic risk assessment of buildings in Europe. Proceedings of the 16th World Conference on Earthquake Engineering, Santiago, Chile, January 9-13, 2017.

[2] R. Maio, G. Tsionis, Seismic fragility curves for the European building stock. Brussels JRC Technical Report, European Commission, 2015.

[3] B. Belletti, E. Martinelli, E. Michelini, M. Tavano, F. Vecchi, Sesmic Risk Assessment of Existing RC Frame Buildings with Shear Walls. Proceedings of the 9th European Workshop on the seismic behaviour of Irregular and Complex Structures (9EWICS), streamed from Lisbon, Portugal, December 15-16, 2020.

[4] P. Ricci, M. T. De Risi, G. M. Verderame, G. Manfredi, Influence of infill distribution and design typology on seismic performence of low- and mid-rise RC buildings. Bulletin of Earthquake Engineering, 11, 1585-1616, 2013.

[5] D. Celarec, P. Ricci, M. Dolšek, The sensitivity of seismic response parameters to the uncertain modelling variables of masonry-infilled reinforced concrete frames. Engineering Structures, 35, 165-177, 2012.

[6] H. B. Kaushik, D. C. Rai, S. K. Jain, Code Apporoaches to seismic Design of MasonryInfilled Reinforced Concrete Frames: A State of the Art. Earthquake Spectra, 22(4), 961983, 2006.

[7] P. G. Asteris, C. Z. Chrysostomou, I. P. Giannopoulos, E. Smyrou, Masonry infilled reinforced concrete frames with openings. Proceedings of $3^{\text {rd }}$ ECCOMAS Thematic Conference on Computational Methods in Structural Dynamics and Earthquake Engineering (COMPDYN 2011), Corfu, Greece, May 26-28, 2011.

[8] F. De Luca, G. M. Verderame, F. Gómez-Martínez, A. Pérez-García, The structural role played by masonry infills on RC building performances after the 2011 Lorca, Spain, earthquake, Bulletin of Earthquake Engineering, 12, 1999-2026, 2014.

[9] N. D. Lagaros, I. A. Naziris, M. Papadrakakis, The influence of masonry infill walls in the framework of the performance-based design. Journal of Earthquake Engineering, 14(1), 57-79, 2010.

[10] L. Decanini, F. Mollaioli, A. Mura, R. Saragoni. Seismic performance of masonry infilled $\mathrm{R} / \mathrm{C}$ frame. Proceedings of 13 th World Conference on Earthquake Engineering, Vancouver, Canada, August 1-6, 2004. 
[11] C. Lima, G. De Stefano, E. Martinelli, Seismic Response of Masonry Infilled RC Frames: Practice-oriented models and open issues. Earthquakes and Structures, 6(4), 409-436, 2014.

[12] M. Dolšek, P. Fajfar, The effect of masonry infills on the seismic response of a four-storey reinforced concrete frame - a deterministic assessment. Engineering Structures, 30, 19912001, 2008.

[13] F. Vecchi, PARC_CL 2.1 crack model for the capacity assessment of new and existing reinforced concrete structures using non-linear finite element analysis. Ph.D. Thesis, Department of Engineering and Architecture, University of Parma, Italy, 2019.

[14] ABAQUS User's Manual. Dassault Systèmes Simulia Corp, Providence, RI, USA.

[15] AICAP Eds, Seismic design of RC buildings - Guide to the application of Eurocode 2, with reference to the Italian Code DM 14.1.2008 (in Italian). Pubblicemento, 2008.

[16] G. Toniolo, M. Di Prisco, Design of structures Vol. 2B - Reinforced concrete. Design for limit states (in Italian), 3rd Edition. Zanichelli, 2009.

[17] B. Belletti, R. Cerioni, I. Iori, Physical Approach for Reinforced-Concrete (PARC) Membrane Elements. ASCE Journal of Structural Engineering, 127, 1412-1426, 2001.

[18] R. Cerioni, I. Iori, E. Michelini, P. Bernardi, Multi-directional modeling of crack pattern in 2D R/C members. Engineering Fracture Mechanics, 75, 615-628, 2008.

[19] P. Bernardi, R. Cerioni, E. Michelini, A. Sirico, Numerical modeling of the cracking behavior of RC and SFRC shear-critical beams. Engineering Fracture Mechanics, 167, 151-166, 2016.

[20] B. Belletti, M. Scolari, F. Vecchi, PARC_CL 2.0 crack model for NLFEA of RC structures under cyclic loadings. Computers and Structures, 191, 165-179, 2017.

[21] B. Belletti, F. Vecchi, Implementation of steel constitutive model including buckling in PARC_CL 2.1 crack model. Proc. of the 5th fib Congress (fib 2018), Melbourne Australia, October 7-11, 2018.

[22] B. Belletti, F. Vecchi F, C. Bandini, C. Andrade, J.S. Montero, Numerical evaluation of the corrosion effects in PC beams without shear reinforcement. Structural Concrete, 2020.

[23] P. Fajfar, A nonlinear analysis method for performance-based seismic design. Earthquake Spectra, 16, 573-592, 2000.

[24] UNI EN 1998-1:2013. Eurocode 8 - Design of structures for earthquake resistance, CEN: Brussels, 2013.

[25] FEMA 356, Prestandard and commentary for the seismic rehabilitation of buildings. Washington DC, USA, 2000. 